\title{
Analysis of Network Reliability Characteristics and Importance of Components in a Communication Network
}

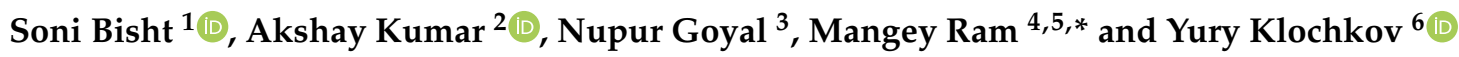 \\ 1 Department of Mathematics, Eternal University, Baru Sahib, Himachal Pradesh 173001, India; \\ sonibisht@eternaluniversity.edu.in \\ 2 Department of Mathematics, Graphic Era Hill University, Dehradun 248002, India; akshaykumar@gehu.ac.in \\ 3 Department of Mathematics, Graphic Era Deemed to be University, Dehradun 248002, India; \\ nupurgoyal.math@geu.ac.in \\ 4 Department of Mathematics, Computer Science and Engineering, Graphic Era Deemed to Be University, \\ Dehradun 248002, India \\ 5 Institute of Advanced Manufacturing Technologies, Peter the Great St. Petersburg Polytechnic University, \\ 195251 Saint Petersburg, Russia \\ 6 Academic Development Management, Peter the Great St. Petersburg Polytechnic University, \\ 195251 Saint Petersburg, Russia; y.kloch@gmail.com \\ * Correspondence: mangeyram@geu.ac.in or drmsswami@yahoo.com; \\ Tel.: +91-135-2642727 or +91-135-2642729 (ext. 256)
}

Citation: Bisht, S.; Kumar, A.; Goyal, N.; Ram, M.; Klochkov, Y. Analysis of Network Reliability Characteristics and Importance of Components in a Communication Network. Mathematics 2021, 9, 1347. https:// doi.org/10.3390/math9121347

Academic Editor: Ioannis

S. Triantafyllou

Received: 20 April 2021

Accepted: 28 May 2021

Published: 11 June 2021

Publisher's Note: MDPI stays neutral with regard to jurisdictional claims in published maps and institutional affiliations.

Copyright: (c) 2021 by the authors. Licensee MDPI, Basel, Switzerland. This article is an open access article distributed under the terms and conditions of the Creative Commons Attribution (CC BY) license (https:// creativecommons.org/licenses/by/ $4.0 /)$.

\begin{abstract}
Network reliability is one of the most important concepts in this modern era. Reliability characteristics, component significance measures, such as the Birnbaum importance measure, critical importance measure, the risk growth factor and average risk growth factor, and network reliability stability of the communication network system have been discussed in this paper to identify the critical components in the network, and also to quantify the impact of component failures. The study also proposes an efficient algorithm to compute the reliability indices of the network. The authors explore how the universal generating function can work to solve the problems related to the network using the exponentially distributed failure rate. To illustrate the proposed algorithm, a numerical example has been taken.
\end{abstract}

Keywords: network reliability; exponential distribution; critical components; Birnbaum importance measure; universal generating function

\section{Introduction}

Network reliability has vital importance at all stages of processing and controlling communication networks. Apart from the reliability of the network, the component's significance is also important. The main purpose of this study is to identify the weak/critical components and quantify the impact of their failures on the network. The flow of signals transmitted from source to sink is called "terminal reliability" or network reliability [1-5]. Zarghami et al. [6] analyzed the exact reliability of infrastructure networks through the decomposition of the network into a set of series and parallel structures.

The universal generating function (UGF) is one of the more noteworthy methods for estimating network reliability, based on various algorithms proposed by Levitin [7]. Lisnianski and Levitin [8] used many real-world multi-state systems in which all the components had different performance levels and failure modes. Negi and Singh [9] studied the non-repairable complex system consisting of two subsystems, say, A and B, connected in series. They also evaluated the reliability, mean time to failure (MTTF), and sensitivity of the considered system with the use of UGF. Renu et al. [10] analyzed the reliability of repairable parallel-series multi-state systems by the application of interval UGF. The authors computed the probabilities of different components, reliability, sensitivity, and MTTF with the use of the Markov process and the Laplace-Steiltjes transform method. The 
problem of uncertainty in the reliability analysis of multistate systems under common cause failure conditions is extended on the basis of a cloud generating function by Jia et al. [11]. Due to the inaccuracy of information about the reliability of data, Gao and Zhang [12] evaluated the reliability of fuzzy multi-state systems. The authors have taken a case study with respect to the reliability analysis of the hydraulic system for the use of fuzzy UGF.

Yeh [13] analyzed the reliability of networks using the binary state network reliability (BSNR) algorithm. Yeh [14,15] was the first to suggest the idea of a directed acyclic multistate network and to examine reliability with the help of a minimal path. Levitin [16] estimated the network reliability problem for acyclic consecutively connected systems with the application of UGF. Yeh [17] improved the reliability of different networks using UGF. The reliability of the multi-state node network and acyclic binary state node network is analyzed using various algorithms deliberating the flows from the source to the destination node. Huang et al. [18] investigated a multi-state distributed network, which contains computers, the internet of things, edge servers, and cloud servers for data transmission, and also developed an algorithm to find the network reliability. Bisht and Singh [19] examined reliability measures like the reliability and MTTF of complex bridge networks from UGF, and provided a comparative study based on network flow. Huang et al. [20] developed an algorithm based on the decomposition approach to evaluate the exact project reliability for a multi-state project network. Birnbaum [21] was the first to introduce the concept of importance measures and their properties.

Component importance in a network is a major factor to compare the effectiveness of components and discuss how they can affect the network's reliability. Hong and Lie [22] evaluated the joint reliability importance of two edges from an undirected network. The authors also presented the relationship between joint reliability and failure, and marginal reliability importance. Armstrong [23] explained the joint reliability importance and showed how two components in a system interact with system reliability. Levitin and Lisnianski [24] studied the importance and sensitivity analysis of multi-state components using the UGF method. The UGF technique provides an effective importance analysis tool for various multistate systems. Amrutkar, and Kamalja [25] discussed different component importance measures for the coherent system and evaluated the importance from a few common system configurations such as series and parallel systems, $k$-out-of- $n$, and consecutive $k$-out-of- $n$ systems. Boland and Neweihi [26] evaluated the importance of components using binary systems; comparisons are made between various measures, and a new measures framework is also suggested. Amrutkar and Kamalja [27] computed the reliability and Birnbaum reliability importance of weighted $k$-out-of- $n$ : G(F) systems. They explained the concept of a weighted Markov Bernoulli trial and conditional weighted Markov Binomial distribution. Chang and Chen [28] described joint structural importance measures, in which the authors have posited an idea about the interaction of the components for contributing to the evaluation of a system's reliability in the consecutive- $k$-out-of- $n$ system. Eryilmaz and Bozbulut [29] computed the reliability importance of the weighted $k$-out-of- $n$ : $\mathrm{G}$ system. The authors analyzed the marginal, joint Birnbaum, and Barlow-Proschan importance of the components in designed systems using UGF. He et al. [30] calculated the three metrics, i.e., Birnbaum measurement, importance, and risk growth factor, for various systems. Gao and Yao [31] described the importance of an individual component in stochastic systems. The importance index for both a component and a group of components has also been studied. Zhu et al. [32] proposed a new type of system design problem, i.e., a multi-type component assignment problem. The Birnbaum importance based on local search methods and genetic algorithms has also been discussed.

Bisht and Singh [33] discussed the reliability of acyclic transmission networks with the help of the Markov process and minimal cut. The authors evaluated the various reliability characteristics from incorporating the Gumbel-Houggard family of copula, supplementary variable technique, and Laplace transforms. They had optimized the reliability analysis with the application of an artificial neural network approach [34]. Ram and Manglik [35,36] analyzed the reliability model of an industrial system having three subsystems, using the 
Markov and supplementary variable technique. Ram and Singh [37] studied the reliability characteristics of a complex system using the Markov process and Gumbel-Houggard family of copula. Ram [38] studied the reliability analysis of various engineering systems using copula and Markov process techniques.

From the above discussions, it is clear that, previously, several researchers had calculated the reliability of different types of networks using the minimal cuts and path methods from a probabilistic approach, such as inclusion-exclusion, product disjoints, and factoring methods. In this paper, the authors discuss the reliability characteristics of a communication network with respect to the different parameters and also propose an algorithm to find the reliability function of the considered network. Numerical examples have been taken to discuss the findings of the communication network as shown in Figure 1, in which different edges have different exponentially distributed failure rates. The notations used in the proposed network have been listed in Table 1.

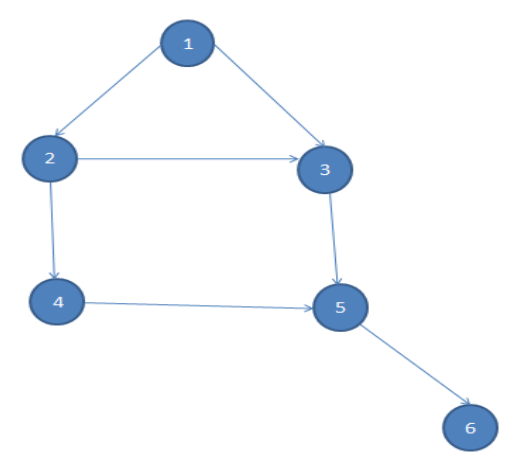

Figure 1. Proposed Network.

Table 1. Notations.

\begin{tabular}{|c|c|}
\hline $\mathrm{u}(\mathrm{z})$ & UGF of zth node of the network \\
\hline $\mathrm{U}(\mathrm{z})$ & UGF of zth subnet node of the network \\
\hline$\otimes$ & Composition operator \\
\hline$p_{m}$ & Probability of $x$ which is equal to $x_{m}$ \\
\hline$r_{n}$ & $n$th node of the considered network \\
\hline$\psi^{\mathrm{n}: \mathrm{m}}$ & Set of nodes receive a signal from the node located at $r_{n}$ \\
\hline$p_{\mathrm{m}, \psi^{\mathrm{n}: \mathrm{m}}}$ & $\begin{array}{l}\text { Probability of the set of node } \psi^{\text {n:m }} \text { receiving a signal directly } \\
\text { from node situated at } r_{n}\end{array}$ \\
\hline$q_{\mathrm{m}, \psi^{\mathrm{n}: \mathrm{m}}}$ & $\begin{array}{c}\text { Probability of the set of nodes } \psi^{\text {n:m }} \text { does not receive a signal } \\
\text { from a node located at } r_{n}\end{array}$ \\
\hline$\omega$ & $\omega$-function operator \\
\hline $\mathrm{R}_{5}$ & Reliability of communication network. \\
\hline$M$ & Number of sink nodes in the proposed network \\
\hline$\lambda_{12} / \lambda_{13} / \lambda_{23} / \lambda_{24} / \lambda_{35} / \lambda_{45} / \lambda_{56}$ & $\begin{array}{l}\text { Failure rate of flow from node } 1 \text { to } 2 / 1 \text { to } 3 / 2 \text { to } 3 / 2 \text { to } 4 / 3 \\
\text { to } 5 / 4 \text { to } 5 / 5 \text { to } 6 .\end{array}$ \\
\hline
\end{tabular}

The rest of this paper is organized as follows: estimation of network reliability using UGF, and algorithms for drawing the reliability function, model description, and numerical illustration of the network are introduced in Section 2. In Section 3, the MTTF of the network with respect to each failure rate has been computed. In Section 4, the authors evaluated the importance of components in the networks from the five metrics. Finally, the conclusions are drawn in Section 5. 


\section{Network Description}

The study of networks is a vast field that deals with the real-life applications of networks in communication, software engineering, industry, mobile ad-hoc, etc. A network is a combination of nodes interconnected with edges. The model of a network is defined by $G=(N, E)$ in which " $N$ " and " $E$ " are the nodes and edges, respectively [2]. In communication networks, the nodes represent computers and the edges, in which the information is transmitted through various transmission lines, connect these computers.

A proposed network consists of a root node where the signal source is placed, and several intermediate nodes receive a signal, which is capable of transmitting the messages to the sink node. The proposed network is used as the communication network.

\section{Universal Generating Function}

The UGF method was first discussed by Ushakov [39] to find the reliability of systems or networks. Levitin [7] presents a detailed description of UGF, composition operator, and network reliability.

A polynomial defines the UGF of a discrete random variable as:

$$
\mathrm{u}(\mathrm{z})=\sum_{\mathrm{m}=1}^{\mathrm{M}} \mathrm{p}_{m} \mathrm{z}^{x_{m}}
$$

where $x$ has $m$ probable values and $\mathrm{p}_{m}$ is the probability of $x$, which is equal to $x_{m}$.

\subsection{Estimation of Network Reliability Using the Universal Generating Function}

Assume a node is placed at position $r_{n}$. If in-state $m\left(1 \leq m \leq \mathrm{M}^{n}\right)$ is the node available for signal transmission from $r_{n}$ to a set of nodes $\psi^{\text {n:m }}$, then it is represented by 1 , otherwise by 0 :

$$
\mathrm{v}_{\mathrm{n}: \mathrm{m}}=\left\{\begin{array}{l}
1, r_{n} \in \psi^{\mathrm{n}: \mathrm{m}} \\
0, r_{n} \notin \psi^{\mathrm{n}: \mathrm{m}}
\end{array}\right.
$$

The node-UGF of $v_{n}$ elements are expressed as:

$$
\mathrm{u}_{\mathrm{i}}(\mathrm{z})=\sum_{\mathrm{m}=1}^{\mathrm{M}} \mathrm{p}_{m, \psi^{\mathrm{n}: \mathrm{m}}} \mathrm{q}_{m, \psi^{\mathrm{n}: \mathrm{m}} \mathrm{z}^{\mathrm{v}}}^{\mathrm{n}: \mathrm{m}}
$$

where $\omega$ is introduced over $u_{i}(z)$ and $u_{i+1}(z)$, the subnet- UGF of $U_{i+1}(z)$ elements are expressed as:

$$
\mathrm{U}_{\mathrm{i}+1}(\mathrm{z})=\omega\left(\mathrm{U}_{\mathrm{i}}(\mathrm{z}), \mathrm{u}_{\mathrm{i}+1}(\mathrm{z})\right)
$$

- From the operator $\omega$, remove the term from UGF where the path does not go through the considered node (unit), and also if the path does not complete from the source node to the considered node.

- For various nodes, collect all similar terms in the resulting UGF.

\subsection{Algorithm for Determining the Reliability of Networks}

For a binary state network (communication network), an algorithm is developed to evaluate network reliability [14] as follows:

Step 1: Find out vectors $v_{n: m}$ corresponding to sets $\psi^{\text {n:m }}$ for the nodes located at the positions $r_{1}, \ldots \ldots, r_{\mathrm{L}-\mathrm{M}}$ in the network.

Step 2: Compute $u_{i}(z)$ of nodes situated at places $r_{1}, \ldots \ldots, r_{L-M}$ from Equation (3).

Step 3: Set $\mathrm{U}_{1}(\mathrm{z})=\mathrm{u}_{1}(\mathrm{z})$.

Step 4: Evaluate $\mathrm{U}_{\mathrm{i}+1}(\mathrm{z})=\left[\omega\left[\mathrm{U}_{\mathrm{i}}(\mathrm{z})\right], \mathrm{u}_{\mathrm{i}+1}(\mathrm{z})\right]$ used for $\mathrm{i}=1, \ldots \ldots, \mathrm{L}-\mathrm{M}-1$.

Step 5: Simplify polynomial $U_{L-M}(z)$, then, using operator $\omega$, obtain the network reliability at the sink (terminal) nodes. 
Here, we have taken two different networks as a case study to examine the reliability characteristics.

\subsection{Model Description}

The possibilities and conditions for moving signal flows are as follows.

(i) If the signal flow from node 1 to node 3 is successful and node 1 to node 2 fails, then the probability becomes $\mathrm{p}_{1: 3} \mathrm{q}_{1: 2}=\left(1-\mathrm{p}_{1: 2}\right)\left(\mathrm{p}_{1: 3}\right)$.

(ii) If signal flow at a node $k$ is interrupted, then the probability becomes $p_{k: \phi}$, where $k=1,2,3,4$, and 5 .

(iii) If the signal flows from node 1 to nodes 2 and 3 , then probability becomes $p_{1:\{2,3\}}=$ $\mathrm{p}_{1: 2} \mathrm{p}_{1: 3}$.

\subsection{Numerical Illustration}

Reliability Computation of Communication Network

Consider a communication network as shown in Figure 1, when the flow of signal originates from node 1 and terminates at node 6 , the considered network having total node $\mathrm{L}=6$ and the sink node $\mathrm{M}=1$, when there exists a node for each subset of $\wedge^{n}(1 \leq n \leq 5)$.

The UGF of the nodes, node 1 , node 2 , node 3 , node 4 , and node 5 are expressed as:

$$
\begin{gathered}
u_{1}(z)=p_{1: \phi}\left(1-p_{1: 2}\right)\left(1-p_{1: 3}\right) z^{(0,0,0,0,0,0)}+p_{1: 2}\left(1-p_{1: 3}\right) z^{(0,1,0,0,0,0)}+p_{1: 3}\left(1-p_{1: 2}\right) z^{(0,0,1,0,0,0)}+p_{1:\{2,3\}} z^{(0,1,1,0,0,0)} \\
\text { When } q=(1-p) \text { then it can also be rewritten as : } \\
u_{1}(z)=p_{1: \phi} q_{1: 2} q_{1: 3} z^{(0,0,0,0,0,0)}+p_{1: 2} q_{1: 3} z^{(0,1,0,0,0,0)}+p_{1: 3} q_{1: 2} z^{(0,0,1,0,0,0)}+p_{1:\{2,3\}} z^{(0,1,1,0,0,0)} \\
u_{2}(z)=p_{2: \phi}\left(1-p_{2: 3}\right)\left(1-p_{2: 4}\right) z^{(0,0,0,0,0,0)}+p_{2: 3}\left(1-p_{2: 4}\right) z^{(0,0,1,0,0,0)}+p_{2: 4}\left(1-p_{2: 3}\right) z^{(0,0,0,1,0,0)}+p_{2:\{3,4\}} z^{(0,0,0,1,1,0,0)} \\
=p_{2: \phi} q_{2: 3} q_{2: 4} z^{(0,0,0,0,0,0)}+p_{2: 3} q_{2: 4} z^{(0,0,1,0,0,0)}+p_{2: 4} q_{2: 3} z^{(0,0,0,1,0,0)}+p_{2:\{3,4\}} z^{(0,0,1,1,0,0)} \\
u_{3}(z)=p_{3: \phi}\left(1-p_{3: 5}\right) z^{(0,0,0,0,0,0,0)}+p_{3: 5} z^{(0,0,0,0,0,1,0)}=p_{3: \phi} q_{3: 5} z^{(0,0,0,0,0,0)}+p_{3: 5} z^{(0,0,0,0,1,0)} \\
u_{4}(z)=p_{4: \phi}\left(1-p_{4: 5}\right) z^{(0,0,0,0,0,0)}+p_{4: 5} z^{(0,0,0,0,0,1,0)}=p_{4: \phi} q_{4: 5} z^{(0,0,0,0,0,0)}+p_{4: 5} z^{(0,0,0,0,1,0)} \\
u_{5}(z)=p_{5: \phi}\left(1-p_{5: 6}\right) z^{(0,0,0,0,0,0)}+p_{5: 6} z^{(0,0,0,0,0,0,1)}=p_{5: \phi} q_{5: 6} z^{(0,0,0,0,0,0)}+p_{5: 6} z^{(0,0,0,0,0,1)}
\end{gathered}
$$

From step 3 of the algorithm, we have

$$
\begin{gathered}
U_{1}(z)=u_{1}(z) \\
\omega\left[U_{1}(z)\right]=p_{1: 2} q_{1: 3} z^{(0,1,0,0,0,0)}+p_{1: 3} q_{1: 2} z^{(0,0,1,0,0,0)}+p_{1:\{2,3\}} z^{(0,1,1,0,0,0)} \\
U_{2}(z)=\left[\omega\left(U_{1}(z)\right), u_{2}(z)\right] \\
=\left(p_{1: 2} q_{1: 3} z^{(0,1,0,0,0,0)}+p_{1: 3} q_{1: 2} z^{(0,0,1,0,0,0)}+p_{1:\{2,3\}} z^{(0,1,1,0,0,0)}\right) \\
\otimes\left(p_{2: \phi} q_{2: 3} q_{2: 4} z^{(0,0,0,0,0,0,0)}+p_{2: 3} q_{2: 4} z^{(0,0,1,0,0,0)}+p_{2: 4} q_{2: 3} z^{(0,0,0,0,1,0,0)}+p_{2:\{3,4\}} z^{(0,0,1,1,0,0)}\right) \\
U_{2}(z)=p_{1: 2} p_{2: 3} q_{2: 4} q_{1: 3} z^{(0,0,1,0,0,0)}+p_{1: 2} q_{1: 3} p_{2: 4} q_{2: 3} z^{(0,0,0,0,1,0,0)}+p_{1: 2} q_{1: 3} p_{2:\{3,4\}} z^{(0,0,1,1,0,0)} \\
+p_{1:\{2,3\}} p_{2: 3} q_{2: 4} z^{(0,0,1,0,0,0)}+p_{1:\{2,3\}} p_{2: 4} q_{2: 3} z^{(0,0,1,0,0,0)}+p_{1:\{2,3\}} p_{2:\{3,4\}} z^{(0,0,1,1,0,0)} \\
\omega\left[U_{2}(z)\right]=\left[p_{1: 2} p_{2: 3} q_{2: 4} q_{1: 3}+p_{1:\{2,3\}} p_{2: 3} q_{2: 4}\right] z^{(0,0,1,0,0,0)}+p_{1: 2} q_{1: 3} p_{2: 4} q_{2: 3} z^{(0,0,0,1,0,0)} \\
+\left[p_{1: 2} q_{1: 3} p_{2:\{3,4\}}+p_{1:\{2,3\}} p_{2: 4} q_{2: 3}+p_{1:\{2,3\}} p_{2:\{3,4\}}\right] z^{(0,0,1,1,0,0)} .
\end{gathered}
$$

Using operator $\omega$, the number of terms in UGF are decreased from 6 to 3. 
The UGF of node 3 is given by:

$$
\begin{gathered}
U_{3}(z)=\left[\omega\left(U_{2}(z)\right), u_{3}(z)\right] \\
=\left(\left[p_{1: 2} p_{2: 3} q_{2: 4} q_{1: 3}+p_{1:\{2,3\}} p_{2: 3} q_{2: 4}\right] z^{(0,0,1,0,0,0)}+p_{1: 2} q_{1: 3} p_{2: 4} q_{2: 3} z^{(0,0,0,1,0,0)}+\left[p_{1: 2} q_{1: 3} p_{2:\{3,4\}}+p_{1:\{2,3\}} p_{2: 4} q_{2: 3}\right.\right. \\
\left.\left.+p_{1:\{2,3\}} p_{2:\{3,4\}}\right] z^{(0,0,1,1,1,0,0)}\right) \otimes\left(p_{3: \phi} q_{3: 5} z^{(0,0,0,0,0,0)}+p_{3: 5} z^{(0,0,0,0,0,0,1)}\right) \\
=\left(p_{12} p_{23} q_{13} q_{24} p_{35} z^{(0,0,0,0,0,1,0)}+p_{1:\{2,3\}} p_{2: 3} q_{2: 4} p_{3: 5} z^{(0,0,0,0,0,0,1)}+p_{1: 2} p_{2:\{3,4\}} q_{1: 3} p_{3: 5} z^{(0,0,0,1,1,0)}\right. \\
\left.+p_{1:\{2,3\}} p_{2: 4} q_{2: 3} p_{3: 5} z^{(0,0,0,0,1,1,0)}+p_{1:\{2,3\}} p_{2:\{3,4\}} p_{3: 5} z^{(0,0,0,1,1,0)}\right) . \\
\omega\left[U_{3}(z)\right]=\left[p_{12} p_{23} q_{13} q_{24} p_{35}+p_{1:\{2,3\}} p_{2: 3} q_{2: 4} p_{3: 5}\right] z^{(0,0,0,0,1,0)}+ \\
{\left[p_{1: 2} p_{2:\{3,4\}} q_{1: 3} p_{3: 5}+p_{1:\{2,3\}} p_{2: 4} q_{2: 3} p_{3: 5}+p_{1:\{2,3\}} p_{2:\{3,4\}} p_{3: 5}\right] z^{(0,0,0,0,1,1,0)} .}
\end{gathered}
$$

Using operator $\omega$, the number of terms in UGF are decreased from 5 to 2.

The UGF of node 4 is given by

$$
\begin{gathered}
\mathrm{U}_{4}(\mathrm{z})=\left[\omega\left(\mathrm{U}_{3}(\mathrm{z})\right), \mathrm{u}_{4}(\mathrm{z})\right] \\
=\left[\mathrm{p}_{12} \mathrm{p}_{23} \mathrm{q}_{13} \mathrm{q}_{24} \mathrm{p}_{35}+\mathrm{p}_{1:\{2,3\}} \mathrm{p}_{2: 3} \mathrm{q}_{2: 4} \mathrm{p}_{3: 5}\right] \mathrm{z}^{(0,0,0,0,1,0)}+\left[\mathrm{p}_{1: 2} \mathrm{p}_{2:\{3,4\}} \mathrm{q}_{1: 3} \mathrm{p}_{3: 5}\right. \\
\left.+\mathrm{p}_{1:\{2,3\}} \mathrm{p}_{2: 4} \mathrm{q}_{2: 3} \mathrm{p}_{3: 5}+\mathrm{p}_{1:\{2,3\}} \mathrm{p}_{2:\{3,4\}} \mathrm{p}_{3: 5}\right] \mathrm{z}^{(0,0,0,0,1,1,0)} \otimes\left(\mathrm{p}_{4: \phi} \mathrm{q}_{4: 5} \mathrm{z}^{(0,0,0,0,0,0)}+\mathrm{p}_{4: 5} \mathrm{z}^{(0,0,0,0,1,0)}\right) . \\
\omega\left[\mathrm{U}_{4}(\mathrm{z})=\left[\mathrm{p}_{12} \mathrm{p}_{2:\{3,4\}} \mathrm{q}_{1: 3} \mathrm{p}_{3: 5} \mathrm{p}_{4: 5}+\mathrm{p}_{1:\{2,3\}} \mathrm{p}_{2: 4} \mathrm{q}_{2: 3} \mathrm{p}_{3: 5} \mathrm{p}_{4: 5}+\mathrm{p}_{1:\{2,3\}} \mathrm{p}_{2:\{3,4\}} \mathrm{p}_{3: 5} \mathrm{p}_{4: 5}\right] \mathrm{z}^{(0,0,0,0,1,0)} .\right.
\end{gathered}
$$

From operator $\omega$, the number of terms in UGF is decreased from 5 to 1.

The UGF of node 5 is given as

$$
\begin{gathered}
\mathrm{U}_{5}(\mathrm{z})=\left[\omega\left(\mathrm{U}_{4}(\mathrm{z})\right), \mathrm{u}_{5}(\mathrm{z})\right] \\
=\left[\mathrm{p}_{12} \mathrm{p}_{2:\{3,4\}} \mathrm{q}_{1: 3} \mathrm{p}_{3: 5} \mathrm{p}_{4: 5}+\mathrm{p}_{1:\{2,3\}} \mathrm{p}_{2: 4} \mathrm{q}_{2: 3} \mathrm{p}_{3: 5} \mathrm{p}_{4: 5}+\mathrm{p}_{1:\{2,3\}} \mathrm{p}_{2:\{3,4\}} \mathrm{p}_{3: 5} \mathrm{p}_{4: 5}\right] \mathrm{z}^{(0,0,0,0,0,1,0)} \\
\otimes\left[\mathrm{p}_{5: \phi} \mathrm{q}_{5: 6} \mathrm{z}^{(0,0,0,0,0,0)}+\mathrm{p}_{5: 6} \mathrm{z}^{(0,0,0,0,0,0,1)}\right] \\
=\mathrm{p}_{12} \mathrm{p}_{2:\{3,4\}} \mathrm{q}_{1: 3} \mathrm{p}_{3: 5} \mathrm{p}_{4: 5} \mathrm{p}_{5: 6} \mathrm{z}^{(0,0,0,0,0,0,1)}+\mathrm{p}_{1:\{2,3\}} \mathrm{p}_{2: 4} \mathrm{q}_{2: 3} \mathrm{p}_{3: 5} \mathrm{p}_{4: 5} \mathrm{p}_{5: 6} \mathrm{z}^{(0,0,0,0,0,1)} \\
+\mathrm{p}_{1:\{2,3\}} \mathrm{p}_{2:\{3,4\}} \mathrm{p}_{3: 5} \mathrm{p}_{4: 5} \mathrm{p}_{5: 6} \mathrm{z}^{(0,0,0,0,0,0,1)} \\
\omega\left[\mathrm{U}_{5}(\mathrm{z})\right]=\left[\mathrm{p}_{12} \mathrm{p}_{2:\{3,4\}} \mathrm{q}_{1: 3} \mathrm{p}_{3: 5} \mathrm{p}_{4: 5} \mathrm{p}_{5: 6}+\mathrm{p}_{1:\{2,3\}} \mathrm{p}_{2: 4} \mathrm{q}_{2: 3} \mathrm{p}_{3: 5} \mathrm{p}_{4: 5} \mathrm{p}_{5: 6}\right. \\
\left.+\mathrm{p}_{1:\{2,3\}} \mathrm{p}_{2:\{3,4\}} \mathrm{p}_{3: 5} \mathrm{p}_{4: 5} \mathrm{p}_{5: 6}\right] \mathrm{z}^{(0,0,0,0,0,1)}
\end{gathered}
$$

Here, using the operator $\omega$, the number of terms in the UGF is decreased from 3 to 1 . $\omega\left[\mathrm{U}_{5}(\mathrm{z})\right]$ is the probability that the signal reaches to sink node 6 via node 5 , which yields the network reliability.

Finally, the reliability of the communication network is obtained as:

$$
R_{5}=p_{12} p_{2:\{3,4\}} q_{1: 3} p_{3: 5} p_{4: 5} p_{5: 6}+p_{1:\{2,3\}} p_{2: 4} q_{2: 3} p_{3: 5} p_{4: 5} p_{5: 6}+p_{1:\{2,3\}} p_{2:\{3,4\}} p_{3: 5} p_{4: 5} p_{5: 6}
$$

It can also be written by incorporating $q=(1-p)$ as:

$$
\begin{gathered}
R_{5}=p_{1: 2} p_{2: 3} p_{2: 4} p_{3: 5} p_{4: 5} p_{5: 6}-p_{1: 2} p_{2: 3} p_{2: 4} p_{3: 5} p_{4: 5} p_{5: 6} p_{1: 3}+p_{1: 2} p_{1: 3} p_{2: 4} p_{3: 5} p_{4: 5} p_{5: 6} \\
-p_{1: 2} p_{1: 3} p_{2: 4} p_{2: 3} p_{3: 5} p_{4: 5} p_{5: 6}+p_{1: 2} p_{1: 3} p_{2: 3} p_{2: 4} p_{3: 5} p_{4: 5} p_{5: 6}
\end{gathered}
$$

The probabilities of the success of components from the network are expressed as:

$$
\mathrm{p}^{1:\{2\}}=\mathrm{e}^{-\lambda_{12} \mathrm{t}}, \mathrm{p}^{1:\{3\}}=\mathrm{e}^{-\lambda_{13} \mathrm{t}}, \mathrm{p}^{2:\{3\}}=\mathrm{e}^{-\lambda_{23} \mathrm{t}} .
$$


Similarly, this can be written for all components present in the bridge network. Now Equation (5) becomes:

$$
\begin{gathered}
\mathrm{R}=\mathrm{e}^{-\left(\lambda_{12}+\lambda_{23}+\lambda_{24}+\lambda_{35}+\lambda_{45}+\lambda_{56}\right) \mathrm{t}}-\mathrm{e}^{-\left(\lambda_{12}+\lambda_{23}+\lambda_{24}+\lambda_{35}+\lambda_{45}+\lambda_{56}+\lambda_{13}\right) \mathrm{t}}+ \\
\mathrm{e}^{-\left(\lambda_{12}+\lambda_{24}+\lambda_{35}+\lambda_{45}+\lambda_{56}+\lambda_{13}\right) t} .
\end{gathered}
$$

The variation of reliability with respect to the time of the proposed network has been obtained from Equation (6). The different values of reliability obtained with respect to time are shown in Table 2, and the corresponding graph has been depicted in Figure 2.

Table 2. Time vs. Reliability.

\begin{tabular}{cc}
\hline Time & Reliability \\
\hline 0 & 1.000000 \\
\hline 1 & 0.343998 \\
\hline 2 & 0.112293 \\
\hline 3 & 0.035484 \\
\hline 4 & 0.010974 \\
\hline 5 & 0.003344 \\
\hline 6 & 0.001008 \\
\hline 7 & 0.000302 \\
\hline 8 & $8.98 \times 10^{-5}$ \\
\hline 9 & $2.66 \times 10^{-5}$ \\
\hline
\end{tabular}

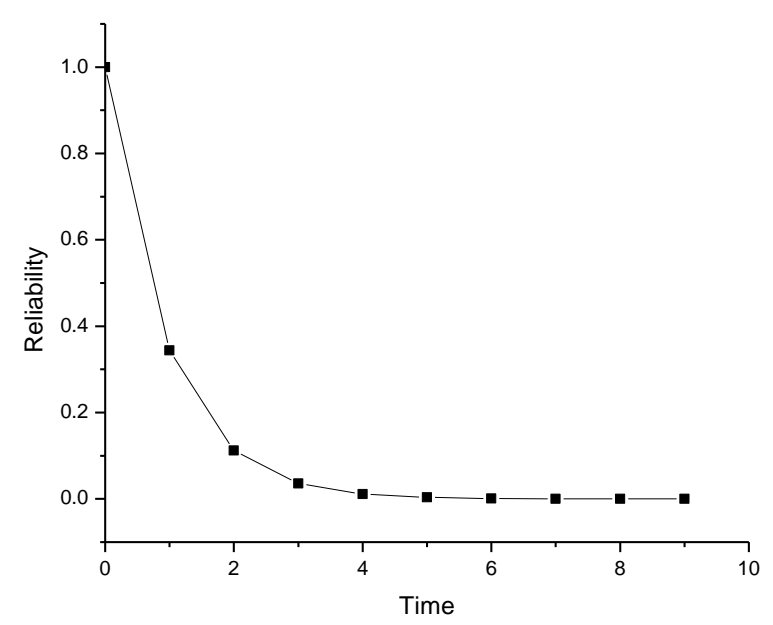

Figure 2. Time vs. Reliability.

\section{Mean Time to Failure (MTTF)}

MTTF is defined as the consecutive failures before some sources are disconnected from the destination. It is the mean time of the network until the first failure occurs, and it is related to reliability $[9,10]$.

MTTF with respect to the failure rate for different components of the network, i.e., 1:2, $1: 3,2: 3,2: 4,3: 5,4: 5,5: 6$ is computed as

$$
=\frac{\operatorname{MTTF}=\int_{0}^{\infty} R(t) d t}{\lambda_{12}+\lambda_{23}+\lambda_{24}+\lambda_{35}+\lambda_{45}+\lambda_{56}}-\frac{1}{\lambda_{12}+\lambda_{23}+\lambda_{24}+\lambda_{35}+\lambda_{45}+\lambda_{56}+\lambda_{13}}+\frac{1}{\lambda_{12}+\lambda_{24}+\lambda_{35}+\lambda_{45}+\lambda_{56}+\lambda_{13}} .
$$


From the above equation, finding the MTTF for the different edges, increasing the value of failure rate with the corresponding parameters $\lambda_{12}$, and setting all other failure rates as constant, one can obtain variation in MTTF with respect to $\lambda_{12}$ from Equation (7); values are given in Table 3, and their corresponding graph in Figure 3. Similarly, for the parameters $\lambda_{23}, \lambda_{24}, \lambda_{35}, \lambda_{45}, \lambda_{56}$ and $\lambda_{13}$, we can obtain variation in MTTF from Equation (7), and all values are given in Table 3 , and their corresponding graph in Figure 3.

Table 3. MTTF of the Communication Network.

\begin{tabular}{cccccccc}
\hline \multirow{2}{*}{ Failure Rate } & $\begin{array}{c}\text { MTTF } \\
\text { w.r.t. } \lambda_{12}\end{array}$ & $\begin{array}{c}\text { MTTF } \\
\text { w.r.t. } \lambda_{23}\end{array}$ & $\begin{array}{c}\text { MTTF } \\
\text { w.r.t. } \lambda_{24}\end{array}$ & $\begin{array}{c}\text { MTTF } \\
\text { w.r.t. } \lambda_{35}\end{array}$ & $\begin{array}{c}\text { MTTF } \\
\text { w.r.t. } \lambda_{45}\end{array}$ & $\begin{array}{c}\text { MTTF } \\
\text { w.r.t. } \boldsymbol{\lambda}_{56}\end{array}$ & $\begin{array}{c}\text { MTTF } \\
\text { w.r.t. } \boldsymbol{\lambda}_{13}\end{array}$ \\
\hline 0.01 & 1.127451 & 0.968313 & 1.077976 & 1.152542 & 1.152542 & 1.198948 & 0.968313 \\
\hline 0.02 & 1.115301 & 0.965819 & 1.066855 & 1.139862 & 1.139862 & 1.185591 & 0.965819 \\
\hline 0.03 & 1.103405 & 0.963391 & 1.055956 & 1.127451 & 1.127451 & 1.172517 & 0.963391 \\
\hline 0.04 & 1.091754 & 0.961026 & 1.045272 & 1.115301 & 1.115301 & 1.159718 & 0.961026 \\
\hline 0.05 & 1.080341 & 0.958721 & 1.034798 & 1.103405 & 1.103405 & 1.147186 & 0.958721 \\
\hline 0.06 & 1.069159 & 0.956476 & 1.024527 & 1.091754 & 1.091754 & 1.134913 & 0.956476 \\
\hline 0.07 & 1.058201 & 0.954287 & 1.014454 & 1.080341 & 1.080341 & 1.122890 & 0.954287 \\
\hline 0.08 & 1.047461 & 0.952153 & 1.004573 & 1.069159 & 1.069159 & 1.111111 \\
\hline 0.09 & 1.036932 & 0.950073 & 0.994879 & 1.058201 & 1.058201 & 1.099568 & 0.952153 \\
\hline 0.10 & 1.026608 & 0.948043 & 0.985366 & 1.047461 & 1.047461 & 1.088255 & 0.950073 \\
\hline
\end{tabular}

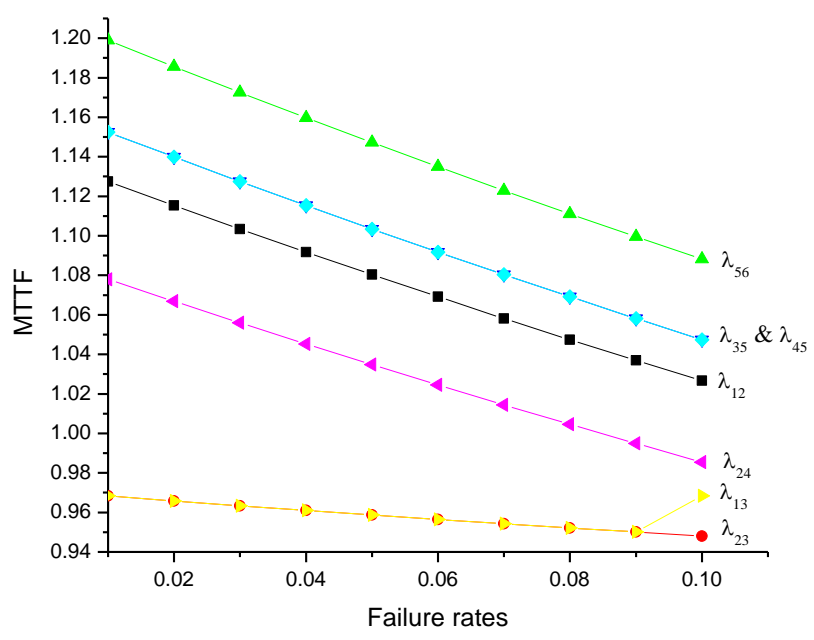

Figure 3. MTTF of the communication network.

\section{Birnbaum Component Importance}

With the development of modern technology, network systems are becoming increasingly complex nowadays. Reliability engineers need a mathematical approach for the complex networks, which can provide the means to define the Birnbaum component importance [21]. The Birnbaum measure [21], denoting the importance of the network adopted by the reliability of the network and the component, is presented in the network:

$$
I_{k}^{B C I}(t)=\frac{\partial R_{N}(t)}{\partial R_{k}(t)}
$$


Here, $R_{N}(t)$ is the reliability function of the network, and $R_{k}(t)$ is the working function of the network component $k$. The Birnbaum component importance of the components, i.e., (BCI, $k$ = edges $(12,13,23,24,35$, and 45$)$ in the communication network is discussed below:

$$
\begin{gathered}
I_{12}^{B C I}(t)=p_{2: 3} p_{2: 4} p_{3: 5} p_{4: 5} p_{5: 6}-p_{2: 3} p_{2: 4} p_{3: 5} p_{4: 5} p_{5: 6} p_{1: 3}+p_{1: 3} p_{2: 4} p_{3: 5} p_{4: 5} p_{5: 6} \\
-p_{1: 3} p_{2: 4} p_{2: 3} p_{3: 5} p_{4: 5} p_{5: 6}+p_{1: 3} p_{2: 3} p_{2: 4} p_{3: 5} p_{4: 5} p_{5: 6} \\
I_{13}^{B C I}(t)=-p_{1: 2} p_{2: 3} p_{2: 4} p_{3: 5} p_{4: 5} p_{5: 6}+p_{1: 2} p_{2: 4} p_{3: 5} p_{4: 5} p_{5: 6}-p_{1: 2} p_{2: 4} p_{2: 3} p_{3: 5} p_{4: 5} p_{5: 6} \\
+p_{1: 2} p_{2: 3} p_{2: 4} p_{3: 5} p_{4: 5} p_{5: 6} \\
I_{23}^{B C I}(t)=p_{1: 2} p_{2: 4} p_{3: 5} p_{4: 5} p_{5: 6}-p_{1: 2} p_{2: 4} p_{3: 5} p_{4: 5} p_{5: 6} p_{1: 3}-p_{1: 2} p_{1: 3} p_{2: 4} p_{3: 5} p_{4: 5} p_{5: 6} \\
+p_{1: 2} p_{1: 3} p_{2: 4} p_{3: 5} p_{4: 5} p_{5: 6} \\
I_{24}^{B C I}(t)=p_{1: 2} p_{2: 3} p_{3: 5} p_{4: 5} p_{5: 6}-p_{1: 2} p_{2: 3} p_{3: 5} p_{4: 5} p_{5: 6} p_{1: 3}-p_{1: 2} p_{1: 3} p_{2: 3} p_{3: 5} p_{4: 5} p_{5: 6} \\
+p_{1: 2} p_{1: 3} p_{3: 5} p_{4: 5} p_{5: 6}+p_{1: 2} p_{2: 3} p_{3: 5} p_{4: 5} p_{5: 6} p_{1: 3} \\
I_{35}^{B C I}(t)=p_{1: 2} p_{2: 3} p_{2: 4} p_{4: 5} p_{5: 6}-p_{1: 2} p_{2: 3} p_{2: 4} p_{4: 5} p_{5: 6} p_{1: 3}+p_{1: 2} p_{1: 3} p_{2: 4} p_{4: 5} p_{5: 6} \\
-p_{1: 2} p_{1: 3} p_{2: 4} p_{4: 5} p_{5: 6} p_{2: 3}+p_{1: 2} p_{2: 3} p_{2: 4} p_{4: 5} p_{5: 6} p_{1: 3} \\
I_{45}^{B C I}(t)=p_{1: 2} p_{2: 3} p_{2: 4} p_{3: 5} p_{5: 6}-p_{1: 2} p_{2: 3} p_{2: 4} p_{3: 5} p_{5: 6} p_{1: 3}+p_{1: 2} p_{1: 3} p_{2: 4} p_{3: 5} p_{5: 6} \\
-p_{1: 2} p_{1: 3} p_{2: 4} p_{3: 5} p_{5: 6} p_{2: 3}+p_{1: 2} p_{2: 3} p_{2: 4} p_{3: 5} p_{5: 6} p_{1: 3 .}
\end{gathered}
$$

Finally, we assume the different probabilities for the different components are defined as:

$$
\mathrm{p}_{1: 2}=0.6, \mathrm{p}_{1: 3}=0.62, \mathrm{p}_{2: 3}=0.7, \mathrm{p}_{2: 4}=0.65, \mathrm{p}_{3: 5}=0.8, \mathrm{p}_{4: 5}=0.72, \mathrm{p}_{5: 6}=0.56
$$

By putting different probabilities for different components in Equations (9)-(14), then we get different values of Birnbaum component importance for different edges as given in Table 4.

Table 4. Values of Birnbaum component importance measure.

\begin{tabular}{cc}
\hline \multicolumn{2}{c}{ Birnbaum Component Importance Measure of a Proposed Network } \\
\hline $\mathrm{I}_{12}^{\mathrm{BCI}}(\mathrm{t})$ & 0.187155072 \\
\hline $\mathrm{I}_{13}^{\mathrm{BCI}}(\mathrm{t})$ & 0.039087360 \\
\hline $\mathrm{I}_{23}^{\mathrm{BCI}}(\mathrm{t})$ & 0.049510656 \\
\hline $\mathrm{I}_{24}^{\mathrm{BCI}}(\mathrm{t})$ & 0.177596928 \\
\hline $\mathrm{I}_{35}^{\mathrm{BCI}}(\mathrm{t})$ & 0.144297504 \\
\hline $\mathrm{I}_{45}^{\mathrm{BCI}}(\mathrm{t})$ & 0.160330560 \\
\hline
\end{tabular}

\subsection{Critical Importance Measure}

In communication networks, critical importance is the probability that component " $\mathrm{k}$ " has occurred and is critical to network failure He et al. [30]. The failure rate of each component is different in any network.

The critical reliability importance $\mathrm{I}_{\mathrm{k}}^{\mathrm{CIM}}(\mathrm{t})$ of the $k$ th component of the network, failure is defined as follows:

$$
\mathrm{I}_{\mathrm{k}}^{\mathrm{CIM}}(\mathrm{t})=\frac{\mathrm{I}_{\mathrm{k}}^{\mathrm{BCI}}(\mathrm{t}) \cdot\left(1-\mathrm{p}_{\mathrm{k}}(\mathrm{t})\right)}{(1-\mathrm{R}(\mathrm{t}))}
$$

Equation (15) shows that the reliability of the communication network is the product of the Birnbaum measure of component $k$ and the ratio of $\left(1-\mathrm{p}_{\mathrm{k}}(\mathrm{t}) /(1-\mathrm{R}(\mathrm{t}))\right.$. The 
critical importance measure of the components can be computed based on Birnbaum measurements.

$$
\begin{aligned}
& \mathrm{I}_{1: 2}^{\mathrm{CIM}}(\mathrm{t})=\frac{\mathrm{I}_{1: 2}^{\mathrm{BCI}}(\mathrm{t}) \cdot\left(1-\mathrm{p}_{1: 2}(\mathrm{t})\right)}{(1-\mathrm{R}(\mathrm{t}))}=0.07961065 . \\
& \mathrm{I}_{1: 3}^{\mathrm{CIM}}(\mathrm{t})=\frac{\mathrm{I}_{1: 3}^{\mathrm{BCI}}(\mathrm{t}) \cdot\left(1-\mathrm{p}_{1: 3}(\mathrm{t})\right)}{(1-\mathrm{R}(\mathrm{t}))}=0.02140485 . \\
& \mathrm{I}_{2: 3}^{\mathrm{CIM}}(\mathrm{t})=\frac{\mathrm{I}_{23}^{\mathrm{BCI}}(\mathrm{t}) \cdot\left(1-\mathrm{p}_{2: 3}(\mathrm{t})\right)}{(1-\mathrm{R}(\mathrm{t}))}=0.0214047 . \\
& \mathrm{I}_{2: 4}^{\mathrm{CIM}}(\mathrm{t})=\frac{\mathrm{I}_{2: 4}^{\mathrm{BCI}}(\mathrm{t}) \cdot\left(1-\mathrm{p}_{2: 4}(\mathrm{t})\right)}{(1-\mathrm{R}(\mathrm{t}))}=0.06430091 . \\
& \mathrm{I}_{3: 5}^{\mathrm{CIM}}(\mathrm{t})=\frac{\mathrm{I}_{3: 5}^{\mathrm{BCI}}(\mathrm{t}) \cdot\left(1-\mathrm{p}_{3: 5}(\mathrm{t})\right)}{(1-\mathrm{R}(\mathrm{t}))}=0.02985399 . \\
& \mathrm{I}_{4: 5}^{\mathrm{CIM}}(\mathrm{t})=\frac{\mathrm{I}_{4: 5}^{\mathrm{BCI}}(\mathrm{t}) \cdot\left(1-\mathrm{p}_{4: 5}(\mathrm{t})\right)}{(1-\mathrm{R}(\mathrm{t}))}=0.046439550 . \\
& \mathrm{I}_{5: 6}^{\mathrm{CIM}}(\mathrm{t})=\frac{\mathrm{I}_{5: 6}^{\mathrm{BCI}}(\mathrm{t}) \cdot\left(1-\mathrm{p}_{5: 6}(\mathrm{t})\right)}{(1-\mathrm{R}(\mathrm{t}))}=0.0936763 .
\end{aligned}
$$

\subsection{Risk Growth Factor}

The risk growth factor (RGF) of component $k$ describes the impact of the failure of component $k$ on network reliability by He et al. [30].

The RGF of component $k$ can be defined as:

$$
\operatorname{RGF}_{\mathrm{k}}(\mathrm{t})=\left(1-\mathrm{R}_{\mathrm{e}_{\mathrm{k}}}(\mathrm{t})\right)-(1-\mathrm{R}(\mathrm{t}))=\mathrm{R}(\mathrm{t})-\mathrm{R}_{\mathrm{e}_{\mathrm{k}}}(\mathrm{t}) .
$$

Here, $\left(1-R_{e_{k}}(t)\right)$ is the network system failure rate when component $k$ is in breakdown condition.

The Risk growth factor of all components is computed as:

$$
\begin{aligned}
& \operatorname{RGF}_{1: 2}(t)=R(t)-R_{e_{1: 2}}(t)=p_{1: 2} p_{2: 3} p_{2: 4} p_{3: 5} p_{4: 5} p_{5: 6}-p_{1: 2} p_{2: 3} p_{2: 4} p_{3: 5} p_{4: 5} p_{5: 6} p_{1: 3}+ \\
& p_{1: 2} p_{1: 3} p_{2: 4} p_{3: 5} p_{4: 5} p_{5: 6}-p_{1: 2} p_{1: 3} p_{2: 4} p_{2: 3} p_{3: 5} p_{4: 5} p_{5: 6}+p_{1: 3} p_{2: 3} p_{2: 4} p_{3: 5} p_{4: 5} p_{5: 6} \\
& \operatorname{RGF}_{2: 3}(t)=R(t)-R_{e_{2: 3}}(t)=p_{1: 2} p_{2: 3} p_{2: 4} p_{3: 5} p_{4: 5} p_{5: 6}-p_{1: 2} p_{2: 3} p_{2: 4} p_{3: 5} p_{4: 5} p_{5: 6} p_{1: 3} \\
& -p_{1: 2} p_{1: 3} p_{2: 4} p_{2: 3} p_{3: 5} p_{4: 5} p_{5: 6}+p_{1: 2} p_{1: 3} p_{2: 3} p_{2: 4} p_{3: 5} p_{4: 5} p_{5: 6} \\
& R_{G F}(t)=R(t)-R_{e_{1: 3}}(t)=-p_{1: 2} p_{2: 3} p_{2: 4} p_{3: 5} p_{4: 5} p_{5: 6} p_{1: 3}+p_{1: 2} p_{1: 3} p_{2: 4} p_{3: 5} p_{4: 5} p_{5: 6} \\
& -p_{1: 2} p_{1: 3} p_{2: 4} p_{2: 3} p_{3: 5} p_{4: 5} p_{5: 6}+p_{1: 2} p_{1: 3} p_{2: 3} p_{2: 4} p_{3: 5} p_{4: 5} p_{5: 6} \\
& \operatorname{RGF}_{2: 4}(t)=R(t)-R_{e_{2: 4}}(t)=p_{1: 2} p_{2: 3} p_{2: 4} p_{3: 5} p_{4: 5} p_{5: 6}-p_{1: 2} p_{2: 3} p_{2: 4} p_{3: 5} p_{4: 5} p_{5: 6} p_{1: 3} \\
& +p_{1: 2} p_{1: 3} p_{2: 4} p_{3: 5} p_{4: 5} p_{5: 6}-p_{1: 2} p_{1: 3} p_{2: 4} p_{2: 3} p_{3: 5} p_{4: 5} p_{5: 6}+p_{1: 2} p_{1: 3} p_{2: 3} p_{2: 4} p_{3: 5} p_{4: 5} p_{5: 6} \\
& \mathrm{RGF}_{3: 5}(\mathrm{t})=\mathrm{R}(\mathrm{t})-\mathrm{R}_{\mathrm{e}_{3: 5}}(\mathrm{t})=\mathrm{p}_{1: 2} \mathrm{p}_{2: 3} \mathrm{p}_{2: 4} \mathrm{p}_{3: 5} \mathrm{p}_{4: 5} \mathrm{p}_{5: 6}-\mathrm{p}_{1: 2} \mathrm{p}_{2: 3} \mathrm{p}_{2: 4} \mathrm{p}_{3: 5} \mathrm{p}_{4: 5} \mathrm{p}_{5: 6} \\
& +p_{1: 3} p_{1: 2} p_{1: 3} p_{2: 4} p_{3: 5} p_{4: 5} p_{5: 6}-p_{1: 2} p_{1: 3} p_{2: 4} p_{2: 3} p_{3: 5} p_{4: 5} p_{5: 6}+p_{1: 2} p_{1: 3} p_{2: 3} p_{2: 4} p_{3: 5} p_{4: 5} p_{5: 6 .} \\
& \operatorname{RGF}_{4: 5}(t)=R(t)-R_{e_{4: 5}}(t)=p_{1: 2} p_{2: 3} p_{2: 4} p_{3: 5} p_{4: 5} p_{5: 6}-p_{1: 2} p_{2: 3} p_{2: 4} p_{3: 5} p_{4: 5} p_{5: 6} p_{1: 3} \\
& +p_{1: 2} p_{1: 3} p_{2: 4} p_{3: 5} p_{4: 5} p_{5: 6}-p_{1: 2} p_{1: 3} p_{2: 4} p_{2: 3} p_{3: 5} p_{4: 5} p_{5: 6}+p_{1: 2} p_{1: 3} p_{2: 3} p_{2: 4} p_{3: 5} p_{4: 5} p_{5: 6} \\
& \operatorname{RGF}_{5: 6}(t)=R(t)-R_{e_{5: 6}}(t)=p_{2: 3} p_{2: 4} p_{3: 5} p_{4: 5} p_{5: 6}-p_{1: 2} p_{2: 3} p_{2: 4} p_{3: 5} p_{4: 5} p_{5: 6} p_{1: 3}+ \\
& \mathrm{p}_{1: 2} \mathrm{p}_{1: 3} \mathrm{p}_{2: 4} \mathrm{p}_{3: 5} \mathrm{p}_{4: 5} \mathrm{p}_{5: 6}-\mathrm{p}_{1: 2} \mathrm{p}_{1: 3} \mathrm{p}_{2: 4} \mathrm{p}_{2: 3} \mathrm{p}_{3: 5} \mathrm{p}_{4: 5} \mathrm{p}_{5: 6} \\
& +\mathrm{p}_{1: 2} \mathrm{p}_{1: 3} \mathrm{p}_{2: 3} \mathrm{p}_{2: 4} \mathrm{p}_{3: 5} \mathrm{p}_{4: 5} \mathrm{p}_{5: 6}
\end{aligned}
$$


From Equations (17)-(23), the values of risk growth factors are tabulated in Table 5.

Table 5. Risk growth factor values.

\begin{tabular}{|c|c|}
\hline \multicolumn{2}{|c|}{ Risk Growth Factor Value for Edges in the Proposed Network } \\
\hline $\operatorname{RGF}_{1: 2}(\mathrm{t})$ & 0.10667704 \\
\hline $\mathrm{RGF}_{2: 3}(\mathrm{t})$ & 0.02868203 \\
\hline $\mathrm{RGF}_{1: 3}(\mathrm{t})$ & 0.03119800 \\
\hline $\mathrm{RGF}_{2: 4}(\mathrm{t})$ & 0.10667704 \\
\hline $\mathrm{RGF}_{3: 5}(\mathrm{t})$ & 0.10667704 \\
\hline $\operatorname{RGF}_{4: 5}(\mathrm{t})$ & 0.10667704 \\
\hline $\operatorname{RGF}_{5: 6}(\mathrm{t})$ & 0.10667704 \\
\hline
\end{tabular}

\subsection{Average Risk Growth Factor}

Average risk growth factor (ARGF) is the average impact of all component failures individually on the network system based on [15]; the average risk growth factor [35] can be formulated as:

$$
\operatorname{ARGF}(\mathrm{t})=\frac{\sum_{\mathrm{k}=1}^{\mathrm{d}} \operatorname{RGF}_{\mathrm{k}}(\mathrm{t})}{\mathrm{n}}=\frac{\sum_{\mathrm{k}=1}^{\mathrm{d}} \mathrm{R}(\mathrm{t})-\mathrm{R}_{\mathrm{e}_{\mathrm{k}}}(\mathrm{t})}{\mathrm{n}}
$$

The average risk growth factor for the considered network is calculated as:

$$
\begin{gathered}
\operatorname{ARGF}(t)=\frac{\mathrm{RGF}_{1: 2}+\mathrm{RGF}_{2: 3}+\mathrm{RGF}_{1: 3}+\mathrm{RGF}_{2: 4}+\mathrm{RGF}_{3: 5}+\mathrm{RGF}_{4: 5}+\mathrm{RGF}_{5: 6}}{7} \\
=0.0847521769 .
\end{gathered}
$$

\subsection{Network Reliability Stability}

The average risk growth factor has a strong relationship with network reliability stability (NRS). When network reliability stability has a value of one, that means network system component failure has little effect on network reliability. However, when network reliability stability has a value of zero, then component failure has a greater impact on the system. Based on Equation (24), the network reliability stability by He et al. [30] is formulated as:

$$
\mathrm{NR}_{\mathrm{S}}(\mathrm{t})=\frac{\mathrm{R}(\mathrm{t})-\mathrm{ARGF}(\mathrm{t})}{\mathrm{R}(\mathrm{t})}
$$

The network reliability stability for the communication network is formulated as:

$$
\begin{gathered}
\mathrm{NR}_{S}(\mathrm{t})=\frac{0.10667704-0.0847521769}{0.10667704} \\
\mathrm{NR}_{S}(\mathrm{t})=0.205525604 .
\end{gathered}
$$

\section{Conclusions}

In this paper, the component's importance and its critical value, network reliability stability using Birnbaum importance, and reliability measures from the UGF method have been discussed. This network reliability study is significant for design engineers and architectures to enhance network performance. The authors also calculate its risk growth factor and average risk growth factor. From Table 2 and Figure 2, the authors found that the reliability of the system decreases as time increases. The MTTF of the network with respect to the failure rate of different edges is tabulated in Table 3, and described by the graphs shown in Figure 3. From the observations, we analyzed that by increasing the value of failure rate, the MTTF is continuously decreasing, but in the case of edge 1:3, MTTF is increasing when the failure rate lies between 0.09 and 0.1. Birnbaum's importance helps us to study the sensitivity of the network. From the analysis of Birnbaum's importance 
performed in Section 5, the authors found from Table 4 that edge 1:2 is the most sensitive and edge 1:3 is the least sensitive flow in the network. The values of the risk growth factor for each component in the networks are tabulated in Table 5. The network stability is computed as 0.2055 , which means the network is working in a degraded condition until the network has approx. $20 \%$ failure. In future studies, different types of probability distribution can be applied for various binary and complex networks.

Author Contributions: Conceptualization, S.B.; methodology, S.B.; software, A.K.; formal analysis, S.B.; investigation, A.K.; writing — original draft preparation, A.K.; writing—review and editing, N.G.; supervision and writing-original draft preparation, M.R.; funding acquisition, supervision, Y.K. All authors have read and agreed to the published version of the manuscript.

Funding: The research is partially funded by the Ministry of Science and Higher Education of the Russian Federation as part of the world-class Research Center program: Advanced Digital Technologies (contract No. 075-15-2020-934 dated 17 November 2020).

Institutional Review Board Statement: Not applicable.

Informed Consent Statement: Not applicable.

Data Availability Statement: Not applicable.

Acknowledgments: Authors are thankful to the Ministry of Science and Higher Education of the Russian Federation for the financial support. Additionally, the authors express their sincere thanks to the referees and editors for their valuable comments and suggestions towards the improvement of the article.

Conflicts of Interest: The authors declare no conflict of interest.

\section{References}

1. Colbourn, C.J. The Combinatorics of Network Reliability; Oxford University Press: New York, NY, USA, 1987.

2. Gertsbakh, I.; Shpungin, Y. Network Reliability and Resilience; Springer Science \& Business Media: Berlin/Heidelberg, Germany, 2011.

3. Ma, R.; Xing, L.; Wang, Y. Performance Analysis of Reed-Solomon Codes for Effective Use in Survivable Wireless Sensor Networks. Int. J. Math. Eng. Manag. Sci. 2020, 5, 13-28. [CrossRef]

4. Verma, P.; Dumka, A.; Vyas, D.; Bhardwaj, A. Reinforcement Learning based Node Sleep or Wake-up Time Scheduling Algorithm for Wireless Sensor Network. Int. J. Math. Eng. Manag. Sci. 2020, 5, 707-731.

5. Shier, D.R. Network Reliability and Algebraic Structures; Clarendon Press: Oxford, UK, 1991.

6. Zarghami, S.A.; Gunawan, I.; Schultmann, F. Exact Reliability Evaluation of Infrastructure Networks Using Graph Theory. Qual. Reliab. Eng. Int. 2020, 36, 498-510. [CrossRef]

7. Levitin, G. The Universal Generating Function in Reliability Analysis and Optimization; Springer: London, UK, 2005; Volume 6.

8. Lisnianski, A.; Levitin, G. Multi-State System Reliability: Assessment, Optimization and Applications; World Scientific Publishing Company: Singapore, 2003; Volume 6.

9. Negi, S.; Singh, S.B. Reliability Analysis of Non-Repairable Complex System with Weighted Subsystems Connected in Series. Appl. Math. Comput. 2015, 262, 79-89. [CrossRef]

10. Renu; Bisht, S.; Singh, S.B. Reliability Evaluation of Repairable Parallel-Series Multi-State System Implementing Interval Valued Universal Generating Function. J. Reliab. Stat. Stud. 2021, 14, 81-120.

11. Jia, J.Z.; Li, Z.; Jia, P.; Yang, Z.G. Reliability Analysis of Common Cause Failure Multistate System Based on CUGF. Math. Probl. Eng. 2020, 2020, 4608124. [CrossRef]

12. Gao, H.; Zhang, X. A Novel Reliability Analysis Method for Fuzzy Multi-State Systems Considering Correlation. IEEE Access 2019, 7, 153194-153204. [CrossRef]

13. Yeh, W.C. An Evaluation of the Multi-State Node Network Reliability using the Traditional Binary-State Networks Reliability Algorithm. Reliab. Eng. Syst. Saf. 2003, 81, 1-7. [CrossRef]

14. Yeh, W.C. A Simple Universal Generating Function Method to Search for All Minimal Paths in Networks. IEEE Trans. Syst. Manand Cybern. Part A Syst. Hum. 2009, 39, 1247-1254.

15. Yeh, W.C. A Simple Universal Generating Function Method for Estimating the Reliability of General Multi-State Node Networks. IIE Trans. 2008, 41, 3-11. [CrossRef]

16. Levitin, G. Reliability Evaluation for Acyclic Consecutively Connected Networks with Multistate Units. Reliab. Eng. Syst. Saf. 2001, 73, 137-143. [CrossRef]

17. Yeh, W.C. A Modified Universal Generating Function Algorithm for the Acyclic Binary-State Network Reliability. IEEE Trans. Reliab. 2012, 61, 702-709. [CrossRef] 
18. Huang, D.H.; Huang, C.F.; Lin, Y.K. Exact Project Reliability for a Multi-State Project Network Subject to Time and Budget Constraints. Reliab. Eng. Syst. Saf. 2020, 195, 106744. [CrossRef]

19. Bisht, S.; Singh, S.B. Signature Reliability of Binary State Node in Complex Bridge Networks Using Universal Generating Function. Int. J. Qual. Reliab. Manag. 2019, 36, 186-201. [CrossRef]

20. Huang, C.F.; Huang, D.H.; Lin, Y.K. Network Reliability Evaluation for a Distributed Network with Edge Computing. Comput. Ind. Eng. 2020, 147, 106492. [CrossRef]

21. Birnbaum, W. On the Importance of Different Components in a Multi-Component System. Multivar. Anal. 1969, 591-592.

22. Hong, J.S.; Lie, C.H. Joint Reliability Importance of Two Edges in an Undirected Network. IEEE Trans. Reliab. 1993, 47, 97-101.

23. Armstrong, M.J. Joint Reliability-importance of Components. IEEE Trans. Reliab. 1995, 44, 408-412. [CrossRef]

24. Levitin, G.; Lisnianski, A. Importance and Sensitivity Analysis of Multi-state Systems using the Universal Generating Function Method. Reliab. Eng. Syst. Saf. 1999, 65, 271-282. [CrossRef]

25. Amrutkar, K.P.; Kamalja, K.K. An Overview of Various Importance Measures of Reliability System. Int. J. Math. Eng. Manag. Sci. 2017, 2, 150-171. [CrossRef]

26. Boland, P.J.; El-Neweihi, E. Measures of Component Importance in Reliability Theory. Comput. Oper. Res. 1995, 22, 455-463. [CrossRef]

27. Amrutkar, K.P.; Kamalja, K.K. Reliability and Importance Measures of Weighted-k-out-of- $n$ : F System. Int. J. Reliab. Qual. Saf. Eng. 2014, 21, 1450015. [CrossRef]

28. Chang, H.W.; Chen, R.J.; Hwang, F.K. The Structural Birnbaum Importance of Consecutive-k Systems. J. Comb. Optim. 2002, 6, 183-197. [CrossRef]

29. Eryilmaz, S.; Bozbulut, A.R. Computing Marginal and Joint Birnbaum, and Barlow-Proschan Importances in Weighted- $k$-out-of- $n$ : G Systems. Comput. Ind. Eng. 2014, 72, 255-260. [CrossRef]

30. He, L.; Cao, Q.; Shang, F. Measuring Component Importance for Network System Using Cellular Automata. Complexity 2019, 2019, 3971597. [CrossRef]

31. Gao, R.; Yao, K. Importance Index of Components in Uncertain Random Systems. Knowl. Based Syst. 2016, 109, 208-217. [CrossRef]

32. Zhu, X.; Fu, Y.; Yuan, T.; Wu, X. Birnbaum Importance Based Heuristics for Multi-type Component Assignment Problems. Reliab. Eng. Syst. Saf. 2017, 165, 209-221. [CrossRef]

33. Bisht, S.; Singh, S.B. Reliability Analysis of Acyclic Transmission Network based on Minimal cuts using Copula in Repair. Proc. Jangjeon Math. Soc. 2019, 22, 163-173.

34. Bisht, S.; Singh, S.B. Reliability and Profit Function Improvement of Acyclic Transmission Network using Artificial Neural Network. Math. Eng. Sci. Aerosp. 2020, 11, 127-141.

35. Ram, M.; Manglik, M. Reliability Measures Analysis of an Industrial System under Standby Modes and Catastrophic Failure. Int. J. Oper. Res. Inf. Syst. 2016, 7, 36-56. [CrossRef]

36. Ram, M.; Manglik, M. Stochastic Biometric System Modelling with Rework Strategy. Int. J. Math. Eng. Manag. Sci. 2016, 1, 1-17. [CrossRef]

37. Ram, M.; Singh, S.B. Analysis of Reliability Characteristics of a Complex Engineering System under Copula. J. Reliab. Stat. Stud. 2009, 2, 91-102.

38. Ram, M. On System Reliability Approaches: A Brief Survey. Int. J. Math. Eng. Manag. Sci. 2013, 4, 101-117. [CrossRef]

39. Ushakov, I. Universal Generating Function. J. Comput. Sci. Syst. 1986, 24, 118-129. 